\title{
Nova espécie de Anacanthus do Brasil (Coleoptera, Cerambycidae, Prioninae, Callipogonini)
}

\author{
Antonio Santos-Silva
}

Museu de Zoologia, Universidade de São Paulo, Caixa Postal 42494, 04218-970 São Paulo, SP, Brasil.

\begin{abstract}
New species of Anachanthus from Brazil (Coleoptera, Cerambycidae, Prioninae, Callipogonini). Anacanthus biramiguelus sp. nov., from Brazil (Rondônia and Mato Grosso), is described and illustrated. A key to the Brazilian species of Anacanthus is added.
\end{abstract}

KEYWORDS. Anacanthus, Cerambycidae, Prioninae, taxonomy.

\section{INTRODUÇÃO}

Lameere (1904) colocou Anacanthus AudinetServille, 1832 como subgênero de Stictosomus AudinetServille, 1832, condição mantida até recentemente. MonNé (2002) considerou-os gêneros distintos.

Descreve-se uma nova espécie de Anacanthus, elevando para quatro o número de espécies conhecidas, das quais apenas A. aquilus Thomson, 1865 não ocorre no Brasil (MonNÉ, 1995).

As siglas mencionadas correspondem às seguintes instituições: MNRJ, Museu Nacional, Universidade Federal do Rio de Janeiro, Rio de Janeiro; MZSP, Museu de Zoologia, Universidade de São Paulo, São Paulo.

\section{Anacanthus biramiguelus sp. nov. \\ (Figs. 1, 2)}

Etimologia. A espécie é dedicada ao Dr. Ubirajara R. Martins (MZSP) e ao Dr. Miguel A. Monné (MNRJ).

Macho (fig. 1). Tegumento castanho de matiz variável. Região dorsal da cabeça longitudinalmente sulcada desde as suturas frontais até a região do occipício (sulco profundo entre os olhos); área entre a borda posterior dos olhos e o occipício com pontuação grossa, cerrada e confluente; área entre os olhos com pontos grossos e dispersos, principalmente em direção ao sulco; pilosidade muito curta e esparsa. Região posterior dos olhos com pontuação densa e anastomosada. Tubérculos anteníferos cerradamente pontuados; ápice arredondado. Fronte e área do clípeo deprimidos, com escultura igual à dos tubérculos anteníferos. Borda anterior do clípeo côncava. Superfície dorsal do labro côncava, pontuada e com pêlos moderadamente longos e abundantes; ápice aguçado. Ápice da gena pouco projetado e aguçado, ou apenas arredondado. Submento suavemente áspero, com pêlos longos e abundantes (mais longos e concentrados em direção à margem anterior); margem anterior obliquamente elevada. Mento com pilosidade e escultura iguais às do submento. Palpos maxilares com pêlos pouco concentrados; segundo artículo mais longo que os demais. Gálea digitiforme, com pilosidade densa, atinge a metade do segundo artículo dos palpos maxilares.

Mandíbulas com carena dorsal larga; pontuação dorsal e lateral grossa e abundante, confluente em direção à base; terço centro-lateral nitidamente expandido e bianguloso próximo à base do dente apical externo; dente apical externo maior e mais aguçado do que o interno; margem interna com um dente grande, de ápice arredondado, próximo ao dente apical interno; pilosidade esparsa e curta nas laterais e relativamente longa e concentrada próximo à margem interna, entre o dente e o côndilo; face ventral suavemente escavada nas laterais.

Antenas glabras, atingem o quinto apical dos élitros. Escapo ultrapassa a borda posterior do olho; face dorsal rugosa na metade anterior, com pontuação anastomosada no quarto seguinte e com pontos grossos e esparsos, entremeados por pontos finos, no quarto apical; face látero-externa fortemente áspera; face láterointerna com pontuação relativamente fina e cerrada; face ventral com pontos grossos na metade anterior e pontos finos na metade posterior, entremeados por grânulos esparsos. Antenômero III atinge, ou quase, o úmero; antenômeros III-IX fina e cerradamente pontuados na região dorsal; III-XI com áreas sensoriais (mais conspícuas em direção ao último antenômero).

Protórax transverso, mais largo na região dos ângulos laterais; ângulos anteriores, laterais e posteriores aguçados e salientes, principalmente os anteriores. Pronoto convexo; borda anterior sinuosa, freqüentemente crenada próxima aos ângulos anteriores; bordas laterais irregularmente crenadas; borda posterior convexa e sinuosa; disco com pontos abundantes nas áreas anteriores e posteriores e quase liso ou liso na área média; laterais com grânulos circunvizinhos aos ângulos anteriores, pontuadas no restante (pontos anastomosados junto aos ângulos posteriores) e com pêlos longos e esparsos próximos às bordas. Prosterno e proepisternos glabros e com grânulos esparsos, mais abundantes e cerrados nos proepisternos. Processo prosternal projetado, destacado e com sulco longitudinal em quase toda extensão; ápice arredondado. Mesosterno subliso, glabro, saliente e elevado na região central em direção ao prosterno. Mesepisternos com pontos grandes, rasos e moderadamente abundantes. Mesepimeros micropontuados. Metasterno com pontos relativamente grandes e esparsos no disco; laterais com 

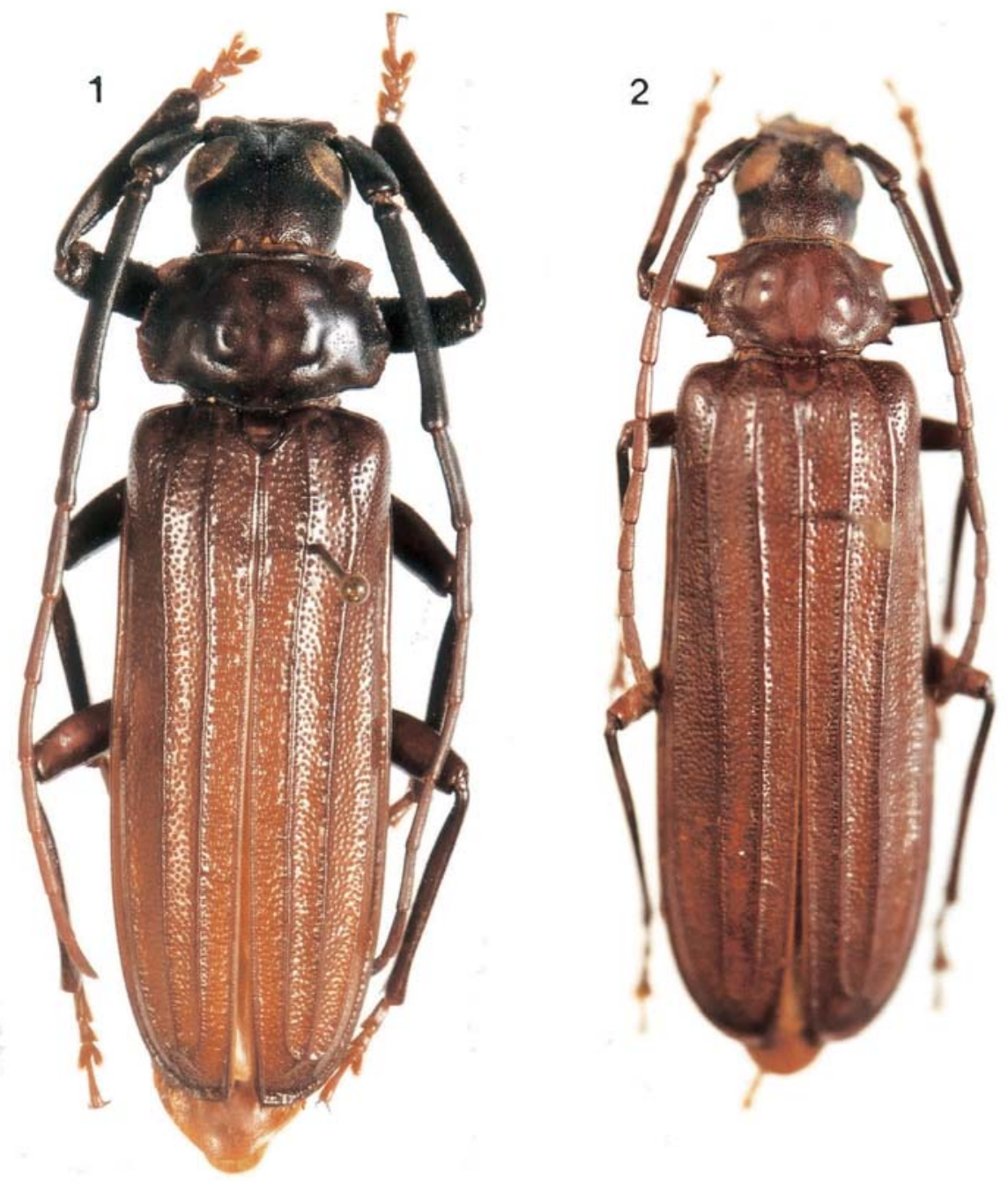

Figs. 1, 2. Anacanthus biramiguelus sp. nov., vista dorsal: 1, holótipo ơ, comprimento 41,1 mm; 2, parátipo $\subsetneq$, comprimento $38,4 \mathrm{~mm}$.

pontos finos abundantes, entremeados por pontos grossos. Metepisternos com escultura igual a das laterais do metasterno. Élitros com pontuação grossa e abundante e quatro carenas fortes e estreitas: a primeira, sutural; a segunda e a terceira estendem-se da base até próximo ao ápice, onde são fundidas, formando um arco; a quarta, apenas indicada até o terço basal, nítida dessa área até sua fusão com a terceira, em geral, pouco antes do ápice do arco formado pela segunda e terceira carenas; ápice sutural com espinho.

Urosternitos I-IV pontuados (pontuação cerrada e anastomosada nas laterais); urosternitos I-III glabros; urosternito IV com pêlos muito curtos e esparsos nas laterais. Urosternito $\mathrm{V}$ com pontos abundantes, mais concentrados lateralmente e no terço apical; pilosidade curta e esparsa nos três quartos basais e longa e abundante no quarto apical; bordas laterais e apical com pêlos longos (mais longos e cerrados na borda apical); ápice com reentrância central. Profêmures ásperos; face dorsal dos mesofêmures com pontos finos e a ventral pontuada na base e gradualmente áspera em direção ao ápice; face dorsal dos metafêmures sublisa, a ventral finamente pontuada (pontos mais cerrados em direção ao ápice). Protíbias largas; face dorsal áspera e com sulco longitudinal nos dois terços basais; face látero-interna fortemente áspera (às vezes, com espinhos curtos) e com escova de pêlos, mais densa e longa em direção ao ápice. Meso- e metatíbias pontuadas; pilosidade da face láterointerna curta, principalmente nas metatíbias. Protarsômeros expandidos.

Fêmea (fig. 2). Pilosidade do submento muito esparsa. Mandíbulas sem ângulos na face externa junto à base do dente apical externo. Antenas atingem o meio dos élitros; escapo apenas pontuado, não alcança a borda posterior do olho. Crenulado lateral do pronoto mais fraco; ângulos anteriores e posteriores mais salientes e aguçados. Ápice do último urosternito truncado. Protíbias não-alargadas e apenas cerradamente pontuadas; pilosidade curta e esparsa na face látero-interna. Protarsômeros não-expandidos.

Variabilidade. Nos machos, os ângulos posteriores do protórax podem ser suavemente obtusos e pouco salientes e a área circunvizinha áspera; o sulco longitudinal do processo prosternal é profundo nos 
espécimes maiores e quase nulo nos de pequeno porte. Em alguns espécimes (machos e fêmeas), a partir do arco formado pela segunda e terceira carenas elitrais, projetase uma pequena carena em direção ao ápice sutural, podendo ou não atingi-lo (mais raramente, há outra carena projetada a partir da região de fusão da quarta com a terceira carena, em direção à margem lateral).

Dimensões em mm ( $\sigma / 9)$. Comprimento total, 28,847,2 / 35,8-39,5; comprimento do pronoto no centro, 4,27,2 / 4,1-5,2; largura do pronoto (entre os ápices dos ângulos laterais), 6,8-12,8 / 8,4-8,8; comprimento elitral, 20,0-31,5/25,0-28,5.

Material-tipo. Holótipo ơ, BRASIL, Mato Grosso: Sinop $\left(12^{\circ} 31^{\prime} \mathrm{S}, 55^{\circ} 37^{\prime} \mathrm{W}\right.$ - BR $163, \mathrm{~km} 500$ a $\left.600,350 \mathrm{~m}\right)$, X.1974, Alvarenga \& Roppa col. (MNRJ). Parátipos: da mesma localidade do holótipo, \&, \&, X.1974, Alvarenga \& Roppa col. (MZSP); 7 đ̛, 6 \&, X.1974, Alvarenga \& Roppa col. (MNRJ); 2 đ, 2 †, X.1976, Alvarenga \& Roppa col. (MNRJ). Rondônia: Vilhena, đै, XI.1987, O. Roppa \& P. Magno col. (MNRJ); 2 ơ, f, X.1990, O. Roppa \& J. Becker col. (MNRJ).

Discussão. Anacanthus biramiguelus assemelhase a A. espiritosantensis (Campos Seabra, 1941) pela forma dos ângulos do protórax, mas difere pela cabeça mais alongada, submento piloso e o metasterno glabro. De $A$. reticulatus (Dalman, 1817), difere pela cabeça mais alongada, mandíbulas alargadas na face láteroexterna, margens laterais do pronoto crenadas e explanadas e protíbias mais longas e gradualmente alargadas para o ápice. A. aquilus Thomson, 1865, registrada apenas para a Colômbia, distingue-se facilmente da nova espécie pela pilosidade conspícua nas antenas.

Chave para as espécies de Anacanthus do Brasil

1. Metasterno piloso A. espiritosantensis (Campos Seabra, 1941)

Metasterno glabro 2

2. Margens laterais do pronoto lisas; ápice elitral inerme A. reticulatus (Dalman, 1817)

Margens laterais do pronoto crenadas; ápice elitral com espinho A. biramiguelus sp. nov.

Agradecimentos. Ao Dr. Miguel A. Monné (MNRJ) pelo empréstimo do material para estudo e ao Dr. Ubirajara R. Martins (MZSP) pelo apoio, incentivo e esclarecimentos.

\section{REFERÊNCIAS BIBLIOGRÁFICAS}

LAMEERE, A. A. 1904. Révision des prionides (Neuvième mémoire - Callipogonines). Annales de la Société entomologique de Belgique, Bruxelles, 48:7-78.

Monné, M. A. 1995. Catalogue of the Cerambycidae (Coleoptera) of the Western Hemisphere. Part XXII. São Paulo, Sociedade Brasileira de Entomologia. 115p.

2002. Catalogue of the Neotropical Cerambycidae (Coleoptera) with known host plant - Part V: subfamilies Prioninae, Parandrinae, Oxypeltinae, Anoplodermatinae, Aseminae and Lepturinae. Publicações Avulsas do Museu Nacional, Rio de Janeiro, 96:1-72. 